Revista Aspas

ppgac - USP

Artigo

\title{
DICOTOMIAS DO ESPAÇO: ABORDAGENS ANTICOLONIAIS NAS PRÁTICAS DE MUJERES CREANDO
}

SPACE DICHOTOMIES: ANTICOLONIAL APPROACHES IN THE PRACTICES OF MUJERES CREANDO

DICOTOMÍAS DEL ESPACIO: ENFOQUES ANTICOLONIALES EN LAS PRÁCTICAS DE MUJERES CREANDO

Murilo Moraes Gaulês

Murilo Moraes Gaulês Doutorando em Artes Cênicas (ECA/USP). Pesquisa em andamento (2020-2024). Teoria e Prática do Teatro. Orientadora: Maria Helena de Araujo Bastos. Terrorista poético. 


\section{Resumo}

O artigo aborda as propostas de rupturas epistemológicas nas relações corpo-espaço-performance desenvolvidas pelo coletivo anarcofeminista Mujeres Creando e sua fundadora Maria Galindo. A partir de conceitos da filosofia anticolonial, com autores como Paul Preciado, Jota Mombaça e Sayak Valência, realiza-se uma análise profunda dessas proposições em contraponto à realidade normativa da compreensão espacial da arte contemporânea ocidentalizada e eurocentrada.

Palavras-chave: Mujeres creando, Maria Galindo, anticolonial, arte urbana, performance

\section{Abstract}

The article addresses the proposals for epistemological ruptures in the body-space-performance relations developed by the anarcho-feminist collective Mujeres Creando and its founder Maria Galindo. Based on concepts of anti-colonial philosophy with authors such as Paul Preciado, Jota Mombaça and Sayak Valência, a deep analysis of these propositions is carried out in counterpoint to the normative reality of the spatial understanding of westernized and Eurocentric contemporary art.

Keywords: Mujeres creando, Maria Galindo, anti-colonial, urban art, performance

\section{Resumen}

El artículo aborda las propuestas de rupturas epistemológicas en las relaciones cuerpo-espacio-performance desarrolladas por el colectivo anarco-feminista Mujeres Creando y su fundadora Maria Galindo. Basado en conceptos de filosofía anticolonial con autores como Paul Preciado, Jota Mombaça y Sayak Valência, se lleva a cabo un análisis profundo de estas proposiciones en contrapunto a la realidad normativa de la comprensión espacial del arte contemporáneo occidentalizado y eurocéntrico.

Palabras-clave: Mujeres creando, Maria Galindo, anti-colonial, arte urbana, performance 
Há pelo menos cinco anos, tenho me debruçado em pesquisar e conhecer indivíduos/coletivos aos quais eu chamo de pessoas que produzem à margem das artes. Tenho usado essa nomenclatura para qualificar um recorte de autoras/es de ações estético-políticas potentes, cuja expressividade parece em muito dialogar com as demandas que nós, artistas das periferias do capitalismo ${ }^{1}$, temos sofrido tanto para confrontar, ao mesmo tempo em que essas/es tais autoras/es não se veem identificadas/os como artistas, ou rechaçam qualquer possibilidade de se verem relacionadas/os com a instituição Arte. Uso esse nome na tentativa de facilitar uma organização conceitual dentro daquilo que estes grupos possuem em comum, ao mesmo tempo em que tento não colonizar suas práticas e saberes dentro de um sistema hegemonicamente eurocentrado e patriarcal como, desafortunadamente, tenho visto em muitas pesquisas em arte e principalmente nas artes cênicas. Já faço mea culpa se falho miseravelmente de antemão com isso. Me parece muito difícil compreender quais movimentos são os mais eficazes na reviravolta rebelde contra as opressões estruturais que marcam nossos registros.

No entanto, olhar de perto e com espírito de assumido ignorante para essas manifestações político-culturais tem se mostrado demasiado potente. São trabalhos que rompem com as normas aparentemente estabelecidas pelos cânones de nossas escolas, que parecem contornar, com uma simplicidade de insurgência perigosa, problemas e tabus que têm emperrado reais inovações nas artes cênicas, assim como um real diálogo com o povo, a classe trabalhadora, os ditos como os de abaixo. Em tempos onde as produções contemporâneas dentro das instituições de arte parecem cada vez mais egocentradas e herméticas, onde a possibilidade política é subtraída até seu esvaziamento para dar espaço apenas aos vislumbres pessoais e neoliberais de um pequeno grupo de artistas, procedimentos como esses surgem como um respiro possível e uma retomada da potência coletiva, rebelde e engajada de se reconfigurar o mundo a partir da inventividade intrínseca das artes.

\footnotetext{
' O termo periferias dos capitalismo tem sido melhor utilizado para referir-se a Estados-Nacionais anteriormente ditos como do Terceiro Mundo.
} 
Esse texto busca aproximar um desses grupos, Mujeres Creando, na tentativa de compartir de sua prática subversiva e de sua metodologia pedagógica, expressiva, política e de ruptura epistemológica.

\section{O início, o contexto e o movimento}

Em meados de 1992, as terras assinaladas como Bolívia começavam a viver, com maior fervor, o marco da ascensão neoliberal que afetaria diretamente a vida política, econômica, social e cultural de todos os povos locais. O Estado-Nação era presidido por Jaime Paz Zamora, integrante do partido MIR Bolivia Libre, atualmente conhecido como MBL (qualquer similaridade não é mera coincidência) ou Movimiento Bolivia Libre. Essa onda neoliberal também culminava com a aplicação de um rigoroso sistema patriarcal que excluía mulheres da vida política e da tomada de decisões sobre suas práticas cotidianas, subtraindo suas possibilidades de produção de autonomia e bem viver. Em resposta a isso, um grupo de mulheres se organiza nas terras assinaladas como a capital, La Paz, e inauguram um dos movimentos feministas mais importantes da América Latina: a Mujeres Creando.

Co-fundado pelas militantes Maria Galindo e Julieta Paredes, o grupo tinha por objetivo produzir ações de variadas práticas e pautas, no intuito de construir coletivamente uma nova linguagem que fosse capaz de lidar com as demandas políticas que seus tempos traziam. Tais ações perpassavam por práticas diversas como grafites, intervenções urbanas, ações de acolhida e acompanhamento a mulheres vulneráveis, atos públicos e até um canal de rádio chamado de Radio Deseo. O caráter inventivo e a potência estéticopolítica de suas ações fizeram com que a Mujeres Creando chamasse a atenção de diversos artistas, galeristas, pesquisadores e produtores de todo o mundo. A figura de Galindo passa a circular pelos maiores eventos e espaços da arte contemporânea mundial, como a 27ª Bienal de Artes de São Paulo (BRA), a 7ª Mostra Internacional de Teatro de São Paulo (BRA) e o Museu Nacional de Arte Centro Sofia (ESP). 
María Galindo é militante anarcofeminista, psicóloga, locutora de rádio e já foi apresentadora de TV. A radicalidade de suas ações performáticas chegaram a levá-la diversas vezes à prisão em sua terra natal, ao mesmo tempo em que abriam as portas dos museus e galerias do mundo. Seu trabalho peculiar consiste em uma abordagem metodológica complexa antissitêmica, anti-imperialista e anti-colonialista de produzir ações diretas que componham um feminismo contemporâneo e latinoamericano.

Conheci e trabalhei com Maria em duas ocasiões: uma em 2018, quando a convidei para ministrar uma residência formativa de despatriarcalização para coletivos da periferia da zona norte de São Paulo; e outra em 2020, na $7^{\mathrm{a}}$ MITsp, onde acompanhei seu laboratório experimental como pesquisador cronista.

Durante esses dois encontros, pude trocar muito sobre a metodologia e procedimentos criativos que Galindo desenvolveu ao longo de quase 30 anos com as Mujeres Creando, e certamente um dos elementos mais importantes de seu projeto de ação está relacionado à forma como ela pensa o espaço.

Segundo Paul B. Preciado,

[...] Galindo criou uma prática artística radical: [...] ela coloca práticas e conhecimentos subalternos das mulheres indígenas em diálogo com as tradições políticas e literárias de anarquismo, feminismo punk e não-branco. Mas o que a arte pode fazer diante de um neocolonialismo autoritário no qual as lógicas do feminismo e da política de identidade indígena foram absorvidas no discurso humanista, religioso e neoliberal como novas estratégias de controle? Galindo responde deslocando a arte dos espaços do mercado e da galeria e trazendo-a de volta ao local onde nasceu: a praça pública, o ritual social. As ações públicas de Mujeres Creando, como a Pasarela Feminista, realizada na cidade de Santa Cruz, Bolívia, em 2014, procuraram confrontar o corpo feminino idealizado branco e heterossexual, uma imagem perpetuada pela grande mídia, por 13 horas de 'rebelião' de mulheres nas ruas da cidade, fazendo discursos enquanto andavam em uma passarela improvisada com roupas que elas mesmas confeccionaram e representavam seus próprios corpos e experiências como mulheres indígenas. (PRECIADO, 2019, s.p., tradução nossa).

Como aponta Preciado, as criações de Galindo para as intervenções com as Mujeres Creando têm uma de suas principais inovações no âmbito da espacialidade. $O$ uso do espaço urbano como local de embate e as 
especificidades com o trato desse mesmo espaço em relação aos corpos das Mujeres Creando produz obras significativamente relevantes, tanto estética quanto politicamente, para a compreensão da cena contemporânea latinoamericana e das produções anticoloniais de grupos dissidentes em produção de autonomia.

Embora sua participação e crítica no meio das artes seja notável, nem Galindo nem as Mujeres Creando se consideram artistas. Auto intitulam-se "agitadoras callejeras" (agitadoras de rua). Galindo afirma rechaçar o mundo das artes porque, segundo ela, as artes servem como intermediário de um projeto de silenciamento de minorias. Por isso encaro Maria Galindo como uma pessoa que produz pela margem das artes. Importante frisar o lugar de onde fala, em respeito ao seu posicionamento político e à sua construção metodológica e conceitual. No entanto, isso não torna as abordagens de Galindo menos importantes para a compreensão de novos modos de agir e criar nas artes cênicas contemporâneas, principalmente quando miramos para o vasto e potente cenário latinoamericano.

Por mais que essa afirmação pareça confusa vinda de uma figura que frequentou grandes eventos de galerias e museus importantes pelo mundo, ela afirma que sua participação nesses espaços está muito distante do centro de suas ações e que ela se utiliza desses convites às instituições para denunciá-las e angariar fundos para sua sobrevivência e para o movimento simultaneamente.

\section{Conceituando dentro e fora}

Olhando mais de perto para a abordagem metodológica da ativista, suas análises em torno do "cenário" utilizado para a realização de suas performances possibilita um aprofundamento político e anti-colonial das relações éticas e estéticas com o espaço "cênico".

O processo criativo de Galindo parte de um processo de renomeação, recurso comumente utilizado pelos movimentos anti-colonialistas. O princípio de renomear consiste em evocar as instâncias normativas que passam desapercebidas e, colocando-as em evidência, remover seu status de normal. 
Nomear a norma é o primeiro passo rumo a uma redistribuição desobediente de gênero e anticolonial da violência, porque a norma é o que não se nomeia, e nisso consiste seu privilégio. A nãomarcação é o que garante às posições privilegiadas (normativas) seu princípio de não questionamento, isto é: seu conforto ontológico, sua habilidade de perceber a si como norma e ao mundo como espelho. Em oposição a isso, "o outro" - diagrama de imagens de alteridade que conformam as margens dos projetos identitários dos "sujeitos normais" - é hipermarcado, incessantemente traduzido pelas analíticas do poder e da racialidade, simultaneamente invisível como sujeito e exposto enquanto objeto. Nomear a norma é devolver essa interpelação e obrigar o normal a confrontar-se consigo próprio, expor os regimes que o sustentam, bagunçar a lógica de seu privilégio, intensificar suas crises e desmontar sua ontologia dominante e controladora. (MOMBAÇA, 2016, p. 11).

Nessa etapa metodológica, Galindo opera um trabalho de observação de dicotomias presentes nas formas e conteúdos que compõem cada performance. Dessa maneira, decupa as estruturas da ação performativa em um processo analítico profundo, a fim de deflagrar suas causas e consequências políticas. Executa, assim, um trabalho cirúrgico e importante de trazer à superfície as normas e cânones que são aceitos nos modos de produção em arte com pouco ou nenhum questionamento por parte de artistas e pesquisadores.

Ao partir do método das dicotomias estruturais, a agitadora evoca não apenas as normas sistemicamente invisibilizadas como também enuncia sua contraparte propositiva, a partir da qual inicia sua plataforma de criação. Com isso, vai mais além dos ditames convencionais da análise anti-colonial, conseguindo encontrar proposição prática concomitante ao movimento teórico que orienta suas criações.

Ao olhar para o espaço cênico, as Mujeres Creando observam a dicotomia presente na relação instituição-rua, e vão nomear esses opostos como "espaço dentro" e "espaço fora", respectivamente.

Nomear os espaços institucionais como "espaço dentro" é uma forma de denunciar o lugar político onde se encontra a esmagadora maioria dos teatros, museus e galerias ao redor do mundo, protegidos por dentro das normas capitalistas neoliberais e patriarcais que legitimam e perpetuam 0 poder que exercem na viabilização de produções artísticas. 
Para facilitar a compreensão dessa extremidade da dicotomia, Galindo faz uma analogia com a jornada que atores e atrizes fazem para ascender aos palcos. Segundo ela, para alcançar os palcos, artistas precisam percorrer por uma íngreme escada em que cada um dos degraus representa um preçoimposição que deve ser assumido no trajeto.

O primeiro degrau é o da instituição. A instituição é uma estrutura racista, misógina, binária e heterossexista que delimita normas e regras para estabelecer poder e controle. Aqui a/o artista se defronta com um rígido protocolo que delimita suas possibilidades de ação, colocando qualquer rebeldia como criminosa, incabível ou deletável daquele lugar. No degrau da instituição são pactuados quais os limites permitidos pelas alfândegas do poder, os quais jamais poderão ser atravessados, violados ou negligenciados. As instituições são hipérboles das ficções de poder, sendo estruturas, estruturadas e estruturantes do mecanismo de opressão sobre populações minorizadas em estado de rebeldia. Não à toa, espaços institucionais têm o poder de legislar sobre as obras que acolhem e o comportamento de seus respectivos artistas criadores, podendo, inclusive, censurar, renomear, alterar, polir, lapidar, cortar ou cancelar o que lhe parecer cabido para manter o seu contrato. $O$ contrato é a alma da instituição. Ali se firmam as relações de posse e pertencimento estabelecidas pelo poder cisheteropatriarcal, muitas vezes disfarçadas por tons mais brandos e termos polidos. Troca-se o impor por sugerir, o mandar por solicitar, o servir por colaborar... Não importa quais sejam os termos, tudo aqui se trata de controle, submissão e manutenção de poderes. Todavia, ainda que a/o artista trafegante, em sua procissão rumo ao palco, consiga sobreviver e adaptar-se a essas condições, chega no segundo degrau, o da disciplina.

Se o degrau da instituição serve como espaço para a delimitação das regras e censuras declaradas, o degrau da disciplina serve como policiamento prático e efetivo dessas regras. O disciplinamento é um processo de subordinação, hierarquia, repetição, controle, mutilação. A prática do disciplinamento incute a ideia de ameaça das consequências por romper com o estatuto colonial das regras institucionais. Repare que não estamos falando de um poder que opera pela violência real, mas pela estetização dessa 
mesma violência para operar mecanismos subliminares de medo, a fim de estabelecer e policiar as coreografias dadas.

Sayak Valência, pesquisadora e performer transfeminista mexicana, nomeia esse fenômeno de capitalismo gore, em alusão ao gênero de cinema que se concentra, deliberadamente, em representações gráficas de sangue e violência, cujo termo é utilizado "como categoria exportável ao âmbito filosófico para a interpretação da episteme da violência contemporânea, de suas lógicas e suas práticas" (VALÊNCIA, 2010, p.25, tradução nossa).

Para Valência, a economia global (leia-se as instituições em geral), operam por meio da estetização da violência como modo de controle, já que empregá-la concretamente resultaria em um extermínio ou afastamento real do indivíduo submisso (o que implicaria no fim da oferta de corpos exploráveis para manter a engrenagem do poder em movimento).

Assim, o degrau do disciplinamento opera por meio de ficções que geram um consciente (paranóico) coletivo, que coloca a devoção às regras institucionais como normalidade indiscutível e inquestionável, doutrinando corpos a perpetuar as coreopolíticas hegemonicamente estabelecidas.

Por fim, antes de chegar ao tão almejado palco, ainda há mais um degrau a ser percorrido pela/o artista agora mutilada/o pelo disciplinamento: o degrau derradeiro da história da arte ou da história colonial da arte.

Seguindo o raciocínio, a escola da história das artes tem por objetivo principal ordenar a construção do cânone, do modelo. A partir da propagação repetitiva de registros embasados em um recorte politicamente selecionado da história, essa escola legitima e desqualifica. As próprias divisões da arte por linguagens (visuais, teatro, dança, música, performance, cinema, etc) faz parte de um projeto modelar de separação e exclusão que facilita o controle das ações e expressividades baseado em um conceito que referencia a história colonial da arte. Tudo o que fuja do modelo passa a não ser considerado e, por mais que ainda se enquadre docilmente dentro da legislação institucional e das rédeas da disciplina, passa a ser ignorado, tratado com completa indiferença. Não é preciso um exercício muito forçoso para compreender que os contornos que desenham esse modelo canônico, em muito influenciados pelo conceito datado do século XIX das belas artes, 
desconsideram todas os conceitos e metodologias desenvolvidos por fora do limite geográfico dos povos colonizadores.

Do ponto de vista metodológico, é possível fazer um grande sacrifício, renunciar aos orgasmos, às comidas, às amigas, às festas, às cores, às raízes, para se chegar ao palco, embora não haja garantia alguma de permanência sobre ele.

Há, inclusive, muita mitologia da arte que nos oferece essa história como algo belo. A trajetória do iconicizado cisne negro de "O Lago dos Cisnes" de Tchaikovski é um de muitos exemplos. Muitas obras de arte são uma ode a esse processo.

Portanto o palco, ou a galeria, ou o museu não é um espaço neutro, mas um espaço construído sobre essas bases e esses contextos. Não casual que o espaço dentro corresponde a uma produção de arte branca, eurocentrada e colonial.

É possível que, até o momento, esse ponto de vista possa causar paúra ou, no mínimo, desconforto a muitos de nós artistas que fomos educados e mutilados dentro das escolas de arte que nos deram tudo aquilo a que juramos acreditar. Muito provável que, até aqui, muitos dos que lêem este texto (e que ainda não tenham desistido da leitura), possam confortavelmente chamar este posicionamento como radical, separatista. Não é isso que importa. O objetivo de Galindo com seu processo de análise e criação consiste em provocar uma ruptura epistemológica para a compreensão dessas instâncias no âmbito prático da vida das coisas. Evidente que há exceções. A própria Maria cita a história de Edith Piaf como um exemplo de desvio da escadaria colonial dos palcos. Mas o fato de haver esses rasgos não significa que esses espaços não sejam o que são e não sirvam ao que servem.

Creio que somente a partir disso, ainda com uma demonstração de respeito por todas as outras práticas e escolhas tomadas que não as que aqui se sugere, seja possível encaminhar para a resposta propositiva que a agitadora de rua dá para tudo isso.

Assim, seguimos.

Como resposta imediata, Maria Galindo sugere que o espaço possível de retomada das rebeldias e insurgência política seja o espaço fora. 
Vale lembrar que o conceito de espaço fora é muito mais complexo do que apenas transportar os trabalhos da instituição para a rua ou expô-la à céu aberto. O teatro de rua, por exemplo, não necessariamente se enquadra como uma ação executada no espaço fora. Em suma, esse modelo recorre aos mesmos sistemas (disciplina, história e colonização) para levar para o espaço urbano o mesmo serviço. Ou seja, não basta ir para rua se você não lidar com um conjunto de fórmulas.

Do ponto de vista da história colonial da arte, o contexto do espaço fora não vale nada. Está no lugar da exclusão, do silêncio, do anonimato, do sem nome. Por isso o espaço fora estará epistemologicamente apoiado no lugar da memória histórica, da memória ancestral.

A memória ancestral habita o cotidiano da vida do povo, podendo ter alguns mecanismos de expressividade que efetuam seu registro e sustentam sua permanência por através das gerações. Um desses mecanismos expressivos mais significativos para o processo de construção do fora é a cultura popular. Para Galindo, existe suma importância em distinguir cultura popular de folclore. A cultura popular é a comida, os afetos, as formas de sentirmos as coisas que não estão escritas e que, convenientemente, estão expulsas das artes. $O$ grande problema que a cultura popular propicia para $\circ$ controle estabelecido pelo dentro é a inexistência de autores. Ninguém é dono da cultura popular e por isso ela pertence ao povo, ao coletivo, o lugar da memória ancestral desprovida de posse. É certo que, vez ou outra, algum artista realiza algum tráfico do excedente dessa memória para as artes no dentro. Por isso que a disputa pelo fora trata de uma disputa de sentidos, de significados, da produção de imaginários coletivos que lidem com as coisas do cotidiano, fortalecendo-as de forma política e expressiva, sem colonizar suas pulsões de desejo.

Para falar no fora é necessário recuperar sua memória ancestral, memória histórica, liberdade, e a partir de então, tomar o espaço. Galindo acredita que não dá para saltar entre esses dois espaços, de um para o outro, pois o mundo da arte te toma muito tempo.

O espaço fora não é exclusividade das artes. É um espaço onde é possível realizar uma operação altamente subversiva do ponto de vista 
epistemológico e criativo, onde se converte uma coisa em outra radicalmente diferente.

Uma pessoa que dorme na rua transforma a rua em sua casa. E ela passa a ser. Se você não é capaz de compreender isso, é um problema seu, não dessa pessoa (como ditam as regras do dentro). Parafraseando uma comerciante ambulante: "a rua é minha casa sem marido e meu trabalho sem patrões".

Por isso, a proposta que aqui se coloca desvia das regras de organização, produção e luta que convencionalmente operamos muitas vezes, crentes de que estamos inventando a revolução. Não se trata de ir à rua por democracia, mas por um espaço de configuração de sentidos diferentes, com outros pilares.

Esse jogo de significados, de sentidos e de valores da rua é a liberdade desse espaço. É um espaço muito complexo, muitíssimo mais complexo do que um palco ou uma parede de galeria ou a folha de um livro.

O que está fora é o que se propõe, ou seja, há que se construir seu próprio palco. Um palco metafórico, por fora do cânone de dentro.

Na Pasarela Feminista. intervenção citada anteriormente por Preciado, as Mujeres Creando utilizam de uma praça pública para oferecer um tapete vermelho para que mulheres em geral possam desfilar. Durante a realização da performance, essas mulheres são convidadas a buscarem algo que realmente lhes interesse falar, na busca de sua voz em primeira pessoa para debater suas reais disputas políticas. Para isso, confeccionam roupas e adereços que ajudem a expressar esteticamente suas denúncias. Galindo chama estes objetos de aparatos de fala, dispositivos que possibilitam evocar as vozes daquelas/es que foram sistematicamente silenciadas/os e que, por estarem em um espaço possível de liberdade, passam a expressar suas verdadeiras demandas políticas.

Apesar de aparentemente simples, essa ação de rua utiliza de todos esses elementos complexos supracitados para promover um espaço de real diálogo e convite com o povo, expondo a lógica da convivência sob as regras de Estados-Nacionais fraturados e amalgamados entre os hábitos da memória ancestral e os aprisionamentos da história colonial. 
Se te interessa o fora, o primeiro que se tem que fazer é escutar, dialogar, compreender. Colocar os ouvidos na terra e sentir os sismos que representam os rasgos, para então evocá-los à superfície. Tem que construir seu espaço em completa liberdade, por fora da lógica canônica. Questionarse: quem te põe os limites? Quem põe os marcos de definição? E compreender que a pergunta dos limites é uma questão ética e política no fora. No dentro é uma pergunta hierárquica.

É preciso debater os efeitos que são produzidos.

Outro elemento que contribui para a construção de uma ação por fora é a noção de hackear, ou seja, compreender que não apenas o dentro pode pegar elementos de fora para restaurar, mas o fora também pode recorrer a seus elementos para desestabilizar suas bases conceituais. Enquanto a lógica colonial se utiliza da importação como estratégia para traficar os elementos culturais dos povos em liberdade, o espaço fora se alimenta pelo hackeamento de suas práticas de silenciamento, destruindo os sentidos e significados que negam a existência, e construindo novos sentidos e significados para uma mesma palavra. Em outros termos, o espaço onde se escreve o fora é o imaginário social, cujos repertórios e acervos só podem ser percebidos por aquele que se vê disposto e disponível para ouvir sem opinar ou corromper, mas ouvir para estar junto e abraçar ao cenário que the é disposto.

As Mujeres Creando, quando saem às ruas com seus aparatos de fala, nos dão uma lição sensível e potente de como recuperar nosso fôlego para produzir além dos limites estruturalmente impostos a nossas criações. Nos convidam a uma nova leitura de mundo e de práxis como artistas vivendo o apocalipse da colônia nas bordas geográficas do capitalismo. E talvez seja por isso que seus processo nos soem tão fortes, seja como for sentida essa força. 


\section{Referências bibliográficas}

GALINDO, Maria. Oficina de Despatriarcalização. Formação CiA dXs TeRrOrlsTxS, Projeto Ditadura Gay, 20 a 23 ago. 2018. Disponível em: https://www.youtube.com/watch?v=oEvZbAvsJaE. Acesso em: 08 maio 2020. GALINDO, Maria. No se puede descolonizar sin despatriarcalizar: teoría y propuesta de la despatriarcalización. Bolivia: Mujeres Creando, [s. a.].

GALINDO, Maria. Sin libertad sexual no hay libertad política. Bolivia: Mujeres Creando, [s. a.].

PRECIADO, Paul B. Future Greats: Maria Galindo. Art Review, v. 71, n. 1, jan. 2019. Disponível em: https://artreview.com/jan-feb-2019-future-greats-mariagalindo/. Acesso em: 15 maio 2020.

MOMBAÇA, Jota. Rumo a uma redistribuição desobediente de gênero e da violência! Disponível em:

https://issuu.com/amilcarpacker/docs/rumo_a_uma_redistribuic_a_o_da_vi. Acesso em: 25 maio 2020.

VALÊNCIA, Sayak. Capitalismo Gore. Espanha: Romaya Valls, 2010. 